\title{
Inhalation Vapor, Powder Dosage Form
}

National Cancer Institute

\section{Source}

National Cancer Institute. Inhalation Vapor, Powder Dosage Form. NCI Thesaurus. Code C149589.

Solid preparation consisting of one or more powders of solid active substance(s) intended for generation of vapor to be inhaled to obtain a local effect. The vapor is usually generated by adding the powder to hot water. 